Supplement of Hydrol. Earth Syst. Sci., 24, 3557-3571, 2020

https://doi.org/10.5194/hess-24-3557-2020-supplement

(c) Author(s) 2020. This work is distributed under

the Creative Commons Attribution 4.0 License.

(c) (1)

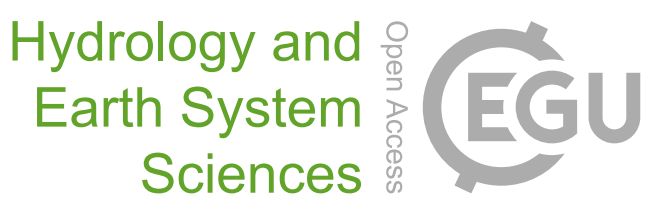

Supplement of

\title{
Understanding coastal wetland conditions and futures by closing their hydrologic balance: the case of the Gialova lagoon, Greece
}

Stefano Manzoni et al.

Correspondence to: Stefano Manzoni (stefano.manzoni@natgeo.su.se)

The copyright of individual parts of the supplement might differ from the CC BY 4.0 License. 


\section{S1. Relation between water level in the Ionian Sea and in the Gialova lagoon}

Water level data in the Ionian Sea were retrieved from the Katakolo sea level monitoring station (37.64 N, 21.32 E), managed by the Hellenic Navy Hydrographic Service (UNESCO Intergovernmental Oceanographic Commission, 2018). Data at five minute resolution were retrieved for the period 2016-2018 and was used to establish correlations between Ionian Sea and Gialova lagoon water levels. To this aim, first, mean hourly values were calculated; second, the two time series were normalized (subtracting the mean and dividing by the standard deviation); third, Pearson correlation coefficients between the two time series were calculated considering lags ranging from 0 (Gialova lagoon water levels vary simultaneously with those in the Ionian Sea) to +100 hours (Gialova lagoon water levels lag behind those in the Ionian Sea). Data was also aggregated at the daily time scale and a similar correlation analysis was conducted (Fig. S1a). The water levels in the Gialova lagoon lag approximately one day behind those of the Ionian Sea. Using hourly data, the Pearson correlation coefficient is maximum ( $r=0.73$; not shown) with a lag of 32 hours; using the daily data, the correlation coefficient is maximum $(r=0.78)$ with a lag of one day (Fig. S1b).

(a)

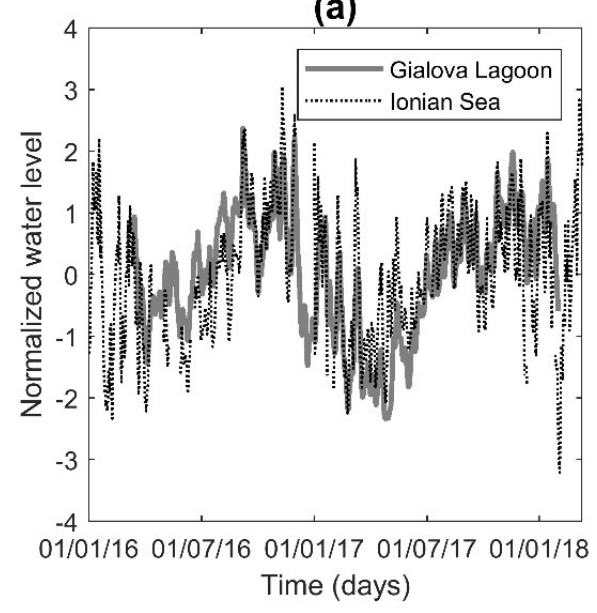

(b)

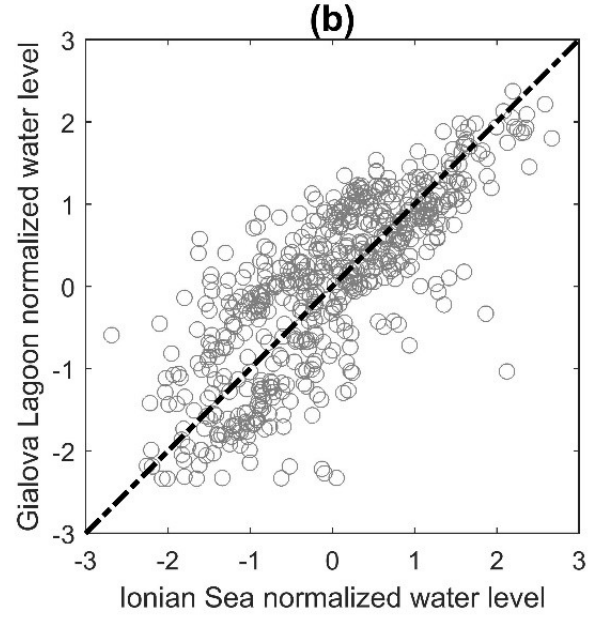

Fig. S1. Relation between mean daily water levels in the Gialova lagoon and in the Ionian Sea. a) Time series of the two water levels after shifting the Sea level series by one day (i.e., the time shift resulting in highest correlation); both time series are normalized by subtracting the mean and dividing by the standard deviation. b) Scatterplot of water levels in the Gialova lagoon as a function of one-day lagged water levels in the Ionian Sea (Pearson correlation coefficient $r=0.78$; the dot-dashed line represents the 1:1 line). 


\section{S2. Relation between salinity point measurements and areal averages}

Areal average salinity was estimated using data from 36 field campaigns including at least four point measurements distributed in the Gialova lagoon or along its shores. From June 1995 to June 1996 salinity was measured at least once every month with a Yellow Springs Instrument Model 33 (Salinity-conductivitytemperature meter) in four locations throughout the lagoon (Arvanitidis et al., 1999). In summer and autumn of 2008, six campaigns were conducted (seven measurement points each). In 2010-2011, four sampling campaigns were held in June, September, December, and March. The measurements were taken using a Hanna $\mathrm{pH} / \mathrm{ORP} / \mathrm{EC} / \mathrm{DO}$ multi-probe. Four sampling points in the lagoon were chosen to match the 1995-1996 campaigns. In 2016-2018, seven additional campaigns were conducted, measuring EC in $>10$ points along the shoreline and using a Decagon CTD-10 or a new Hanna multi-probe. These two sensors were used interchangeably as their electrical conductivity measurements were undistinguishable (readings from the former probe scale linearly with readings from the latter, with a slope 1.04 (intercept set to zero), and a coefficient of determination of the regression $\left.R^{2}=0.9997\right)$. It was not possible to compare the performance of equipment used in 2016-2018 and in the earlier campaigns.

Data of salinity for each campaign was spatially averaged using the Thiessen polygon method (Brassel and Reif, 1979), and spatially interpolated using the Inverse Distance Weighting (IDW) method (Shepard, 1968; Lancaster and Salkauskas, 1986). Thiessen polygons and IDW were calculated for each campaign using ArcMap 10. The areal average value of salinity for the whole lagoon was calculated for each campaign using the weighted area of each Thiessen polygon. Areal estimates were compared to salinity measured at the central point of the lagoon (in 2016-2018), or to salinity values interpolated using IDW and the field campaign measurements (for years before 2016, when continuous recording of salinity was not available). Fig. S2 shows the correlation between the central point measurements and the spatial averages, and demonstrates that the point concentration measurements used are representative of the whole lagoon. The linear regression shown in Fig. S2 was used to scale-up point measurements to the whole lagoon area. Additional information on the spatial variability of water quality parameters can be found in Classon (2017) and Lundmark (2018).

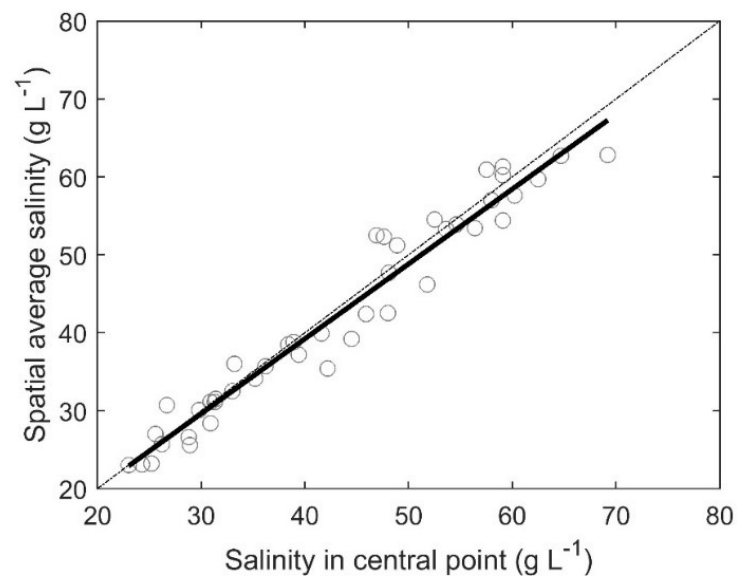

Fig. S2. Correlation between point measurements of salinity in the central site and the spatially averaged salinity of the Gialova lagoon. The solid and dot-dashed lines are the least square linear regression of the data $\left(y=0.96 x+0.82 ; R^{2}=0.95\right)$ and the $1: 1$ line, respectively. 


\section{S3. Meteorological and water quality data gap filling}

Rainfall data measured at the main meteorological station on the Southern shore of the lagoon had significant gaps due to rain gauge malfunctioning. Instead of gap-filling that rainfall time series, we used data from a nearby rain gauge of the same type, located in an olive orchard approximately $5 \mathrm{~km}$ North-East of the main meteorological station. For the 250 days during which both rain gauges worked, their time series were highly correlated (Pearson correlation coefficient $r=0.92 ; \mathrm{p}<0.0001$ ), and the slope of the least square regression line between rainfall at Gialova lagoon and at the olive orchard site was 1.01 (intercept set to zero).

A data logger failure on DOY 286 of 2017 caused loss of water quality and wind speed measurements from the central point in the Gialova lagoon. Missing data from that date to DOY 31 of 2018 were gap-filled using the electrical conductivity time series from the Northern measurement site, which is well-correlated with that from the central measurement site (Fig. S3). Wind speed data were gap-filled using data from the fully automated actinometric-meteorological station established by NOA/IERSD in 2016 at Methoni site, next to the HNMS's station (National Observatory of Athens, 2019). This station is located at higher elevation than sea level, but daily data series exhibit good correlations with the data from the meteorological station at the Gialova lagoon. Pearson correlation coefficients (and p values) for air temperature and relative humidity are $0.99(\mathrm{p}<0.0001)$ and 0.90 $(\mathrm{p}<0.0001$; relative humidity values are higher at the Gialova lagoon due to the proximity to water). To fill gaps in our wind speed record, a linear regression between the wind speed at Methoni and in the centre of Gialova lagoon was established using data till DOY $286\left(y=0.50 x+0.86 ; \mathrm{R}^{2}=0.49\right)$. We did not use wind speed data from the same meteorological station used for rainfall because they were lower (the station is inland and located in an orchard with trees affecting wind patterns).

(a)

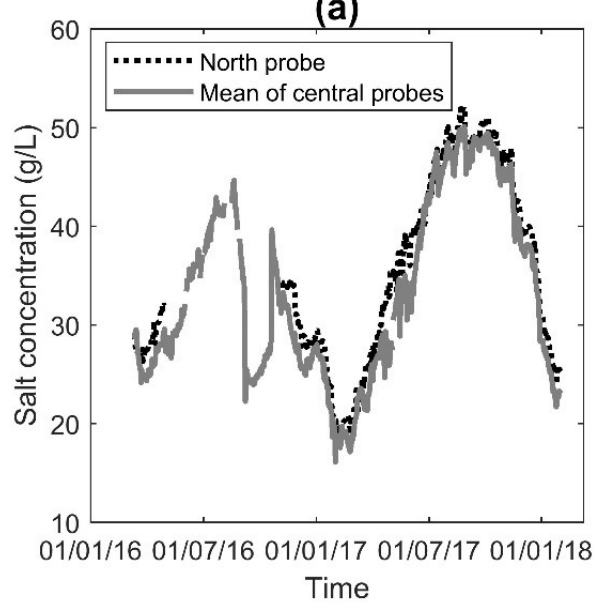

(b)

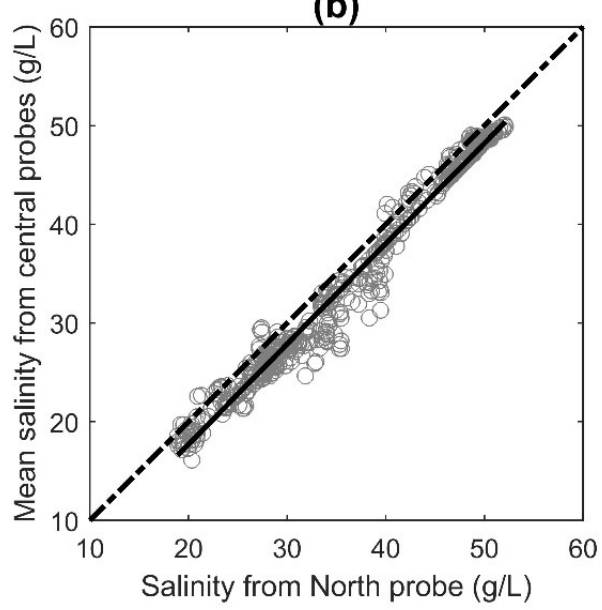

Fig. S3. a) Time series of salt concentrations measured at the central (mean of two probes at different depth) and Northern sites. b) Correlation between salinity at the two sites and regression line used for gap-filling of the time series from the central site probes $\left(y=1.02 x-2.86 ; R^{2}=0.96\right)$; the dot-dashed line represents the $1: 1$ line. 


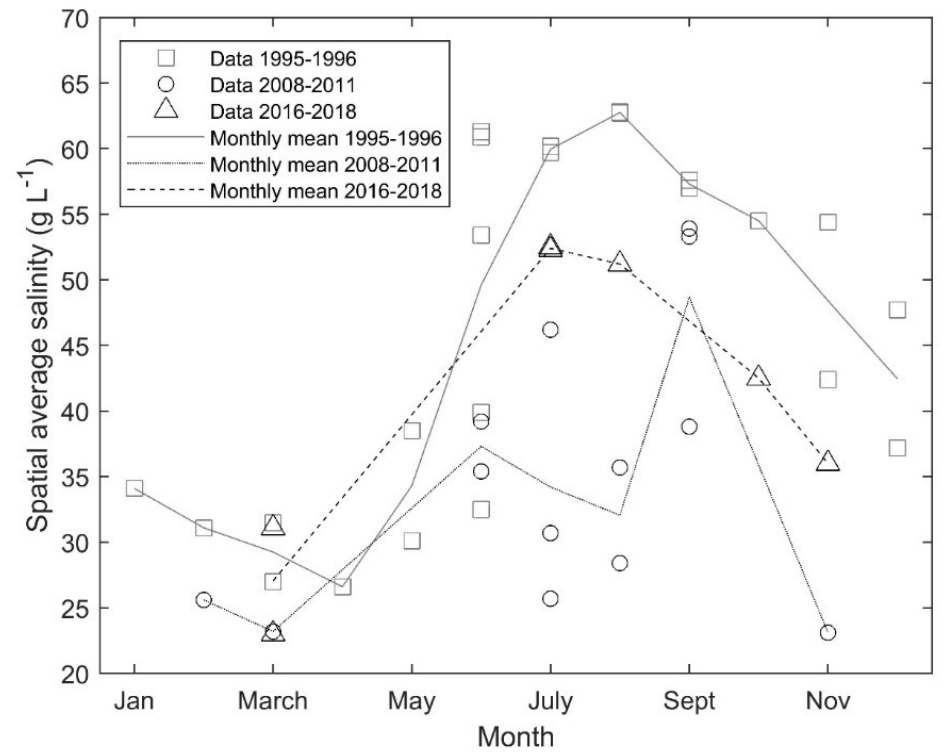

Fig. S4. Seasonal pattern in areal average salinity measured during field campaigns in 1995-1996, 20082011, and 2016-2018. Broken lines connect the monthly mean salinity values for each campaign. Point measurements shown in Fig. 2d are not included. 


\section{References}

Arvanitidis, C., Koutsoubas, D., Dounas, C., and Eleftheriou, A.: Annelid fauna of a Mediterranean lagoon (Gialova lagoon, south-west Greece): community structure in a severely fluctuating environment, Journal of the Marine Biological Association of the United Kingdom, 79, 849-856, undefined, 1999.

Brassel, K. E., and Reif, D.: A Procedure to Generate Thiessen Polygons, Geographical Analysis, 11, 289-303, 10.1111/j.1538-4632.1979.tb00695.x, 1979.

Classon, A.: Seasonal salinity variations and hydrological conditions of the Gialova lagoon, MSc, Department of Physical Geography, Stockholm University, Stockholm, 44 pp., 2017.

Lancaster, P., and Salkauskas, K.: Curve and Surface Fitting. An Introduction, Academic Press, London, 280 pp., 1986.

Lundmark, K.: The spatial variability of salinity and water flux estimates in Gialova lagoon, Greece, MSc, Department of Physical Geography, Stockholm University, Stockholm, 42 pp., 2018.

Methoni site on-line information (dataset obtained from personal communication): http://www.meteo.noa.gr/WeatherOnLine/s_Methoni/meteo_tableEN.html, access: 01/07/2019, 2019.

Shepard, D.: A two-dimensional interpolation function for irregularly-spaced data, Proceedings of the $196823 \mathrm{rd}$ ACM national conference, 1968.

Sea level station monitoring facility: http://www.ioc-sealevelmonitoring.org/index.php, access: 27/11/2018, 2018. 